\title{
A ILHA AMAPÁ - PANORAMA ECOLINGUÍSTICO DA FRONTEIRA FRANCO-BRASILEIRA
}

\author{
Kelly Cristina Nascimento Day
}

\begin{abstract}
RESUMO
Este artigo apresenta um panorama da fronteira franco-brasileira a partir dos fundamentos epistemológicos da Ecolinguística. $\mathrm{O}$ aparato teórico-metodológico utilizado na formatação deste quadro tem por base a perspectiva ecolinguística de Calvet (1999), a abordagem ecossistêmica proposta por Couto (2007), além dos fundamentos metodológicos da pesquisa descritiva de cunho etnográfico.
\end{abstract}

PALAVRAS-CHAVE: Política Linguística; Ecolinguística; Fronteira franco-brasileira.

\section{Considerações iniciais}

$s$ processos de globalização e de abertura da economia, a comunicação intercultural e o alto ritmo de progresso científico e tecnológico exercem pressóes cada vez maiores sobre nossas vidas, exigindo o desenvolvimento de competências em uma ou mais línguas estrangeiras que possibilitem a participação em igualdade de condições na cultura global, sem perder o sentido de pertencimento a uma dada cultura.

O panorama traçado neste trabalho se insere em um contexto relacional interdisciplinar entre ecolinguística e política linguística, tendo como eixo central o meio ambiente fronteiriço e o uso social das línguas em presença. A discussão proposta tem como pano de fundo a adoção de uma mesma política de ensino de línguas estrangeiras para todo o território brasileiro.

Alinhada à compreensão de Dutra (2011, p.449) consideramos que "para melhor entender o ensino de línguas no país, devemos não somente considerar 
as leis, mas também os espaços (...) onde esse ensino acontece”, analisando não apenas quem somos e quem são nossos alunos, mas também que relaçôes estabelecemos com outros povos ao longo de nossa história, que contexto nos atrai ou nos afasta de determinadas línguas e de que modo esta ou aquela língua podem contribuir para a melhoria da qualidade de vida de nossa população.

Nesse âmbito, vislumbramos que o aporte que nos dá atualmente a ecologia linguística, que considera a língua no contexto em que está inserida, é de suma importância para a compreensão da dinâmica ecolinguística da fronteira franco-brasileira.

\section{Fundamentos da ecolinguística}

Desde o início dos anos 1980, diferentes linguistas têm assumido uma abordagem, que se reivindica ecológica, da linguística. Trata-se de uma abordagem interacionista e integracionista que busca dar conta, em diferentes níveis, de todas as inter-relações entre as línguas, os homens e o meio ambiente.

Emprestada da biologia, em que é comumente compreendida como "as interaçóes entre os diferentes organismos e seu meio ambiente natural" (COUTO, 2009, p. 26), a ecologia engloba, fundamentalmente, o conceito de ecossistema: "o conjunto formado pelos seres vivos e seu meio ambiente, considerados como um todo, e suas inter-relaçóes" (COUTO, 2009, p. 26).

Situada na interdisciplinaridade, a Ecologia Linguística, para alguns, ou a Ecolinguística ${ }^{1}$, para outros, aborda as questóes linguísticas, lançando mão da contribuição de diferentes disciplinas, tais como a biologia, a genética, a geografia, a economia, a linguística, a sociologia, a história, etc.

A Ecologia Linguística toma como paradigma tudo o que se relaciona à evolução das estruturas linguísticas, como o nascimento de novas variedades

1 A primeira menção feita à ecologia das línguas ou ecolinguística aparece no título de uma apresentação oral feita por Einar Haugen em agosto de 1970, intitulada "On the ecology of language" e publicada no ano seguinte sob o título de "The ecology of languages", considerado atualmente como texto fundador da disciplina. Ele a define como "[...] o estudo das interaçôes entre qualquer língua dada e seu meio ambiente. [...]. O verdadeiro meio ambiente de uma língua é a sociedade que a utiliza como um de seus códigos. [...] A Ecologia da língua é determinada primeiramente pelos povos que a aprendem, a utilizam e a transmitem para outros" (HAUGEN, 1972, p. 325, tradução nossa). 
linguísticas (falares urbanos, dos jovens, crioulos) e a vitalidade das línguas, desde o seu nascimento, sua evolução, até a morte. E, principalmente, ela considera a coexistência de línguas diversas em um mesmo território, a competição por um domínio de uso e suas interaçôes, sem esquecer os usuários das línguas que são os falantes.

Calvet (1999) emprega o termo "Ecologia das línguas" para sublinhar a importância do estudo das línguas em seu meio ambiente social, político, econômico ou cultural. $\mathrm{Na}$ concepção de Calvet, a abordagem ecolinguística consiste em "estudar as relaçooes entre as línguas e seu meio ambiente, ou seja, primeiro as relações entre as línguas em si mesmas, depois entre as línguas e a sociedade" (CALVET, 1999, p.17. Tradução nossa).

Calvet (1999) adota os termos e as representações da Ecologia contemporânea e analisa o sistema das línguas do mundo a partir de três níveis: o da língua, o da população e o do meio. Ele define que "as línguas equivalem às espécies, se organizam em populações que estão em relação constante com seu meio e evoluem em reação aos estímulos provenientes deste meio" (CALVET, 1999, p. 102. Tradução nossa).

Nesse sistema ecolinguístico, as línguas se multiplicam, variam, se cruzam, se influenciam, colocam-se em concorrência ou em convergência. Este sistema está em inter-relação com o meio, que "está constituído pela organização social, pela dimensão dos grupos de falantes, pelas funçóes ocupadas pelas línguas, pelo papel social de seus falantes, pelo grau de plurilinguísmo deles", etc. (CALVET, 1999, p. 102. Tradução nossa), fatores que podem exercer grande influência sobre a forma e o status das línguas.

Nesse sentido, o autor propóe uma ecologia das línguas que consiga dar conta das diferenças de status entre as línguas e organizá-las em um modelo ecológico e gravitacional, permitindo dar conta da relação de força entre as línguas, além de analisar com clareza as tendências ao monolinguismo de um sistema mundial de comunicação.

De acordo com o modelo gravitacional de Calvet (1999), em torno de uma língua hipercentral, o inglês, cujos falantes têm uma forte tendência monolíngue, gravitam uma dezena de línguas supercentrais, cujos falantes, quando bilíngues, tendem a falar uma língua de mesmo nível ou o inglês. Em torno destas línguas supercentrais, gravita uma centena de línguas centrais, que, por sua vez, constituem o centro de gravitação de milhares de outras línguas periféricas. 
Seguindo a linha inaugurada por Haugen (1972), Couto (2009, p.11) emprega o termo Ecolinguística para referir-se ao "estudo das relações entre língua e meio ambiente", conceito já empregado, anteriormente, por Calvet (1999) ao tratar da "ecologia das línguas do mundo".

Segundo Couto (2009), a abordagem ecolinguística parte do grupo social, povo (p) que vive e convive em determinado território (T) com o objetivo de averiguar como os membros desse povo interagem por meio da língua (L).

Nesse ecossistema denominado Ecossistema Fundamental da Língua (EFL), estão em relação direta um povo, [que vive em] um território e [interage por meio de] uma língua. No cerne deste conjunto que conforma o EFL, povo e território compóem o meio ambiente linguístico.

Esse ecossistema maior compreende três outros: o ecossistema social, o ecossistema mental e o ecossistema natural da língua, no interior dos quais estão os respectivos meios ambientes.

O meio ambiente social é constituído pela língua em relação aos membros da população, organizados socialmente; o meio ambiente mental engloba a totalidade formada pela língua e suas inter-relaçôes com o cérebro; e o meio ambiente natural constitui-se do conjunto formado pela língua e seu entorno físico.

$\mathrm{Na}$ análise da língua pelo viés da Ecolinguística proposta por Couto (2007, 2009, 2012), alguns conceitos da ecologia ganham destaque, entre eles o de "diversidade", indicando que quanto mais espécies houver, mais rico, forte e duradouro será o ecossistema; o de "totalidade", implícito na noção de "todo" de ecossistema; o de "adaptação", cujo princípio é o da adaptação constante dos organismos ao meio ambiente a fim de evoluir, princípio que explica, entre outras coisas, a necessidade de aprendizagem de uma nova língua para adaptar-se a uma nova comunidade de fala e respectiva comunidade de língua; e o conceito de "evolução", que se traduz nas transformaçóes que sofrem as línguas ao longo do tempo.

Comumente utilizada para explicar como uma língua interfere na outra, ou ainda, para mostrar como línguas híbridas se teriam formado, a perspectiva ecolinguística está sendo usada aqui neste trabalho não para tratar destes fenômenos inerentes ao contato linguístico, mas para mostrar que os dados 
que compóem o ecossistema fundamental de uma ou mais línguas em um território dado são de extrema relevância para o estabelecimento de uma política de ensino de línguas condizente com as expectativas da(s) comunidade(s) envolvida(s).

Todo fenômeno linguístico tem seu espaço de contextualização e, nesse sentido, pode-se dizer que o contexto pode influenciar os processos linguísticos por meio de diferentes elementos condicionantes. Um engajamento levado a sério na perspectiva ecolinguística, a nosso ver, implica conceder lugar de centralidade na descrição do contexto e de suas relações ecossistêmicas com as línguas. Assim, em uma análise ecolinguística, o ponto de vista centralizador é exatamente o do contexto, no qual os processos linguísticos, as relaçóes sociais, culturais e afetivas, desenvolvidas entre os sujeitos, são elementos determinantes e determinados.

\section{Amapá - uma "ilha" na faixa de fronteira brasileira}

Compreender o papel das línguas estrangeiras e a importância da língua francesa no seio da sociedade amapaense não se efetiva, objetivamente, sem que abordemos, mesmo que em linhas gerais, a história sociolinguística dessa comunidade, ou que esbocemos um quadro sociopolítico e sócio-histórico que permita estabelecer, em uma linha temporal, as relaçóes que se desenharam na faixa de fronteira que, ao mesmo tempo, separa e aproxima o Amapá da Guiana Francesa. É essa ancoragem sócio-histórica, econômica e geopolítica que nos permitirá apreender alguns elementos constitutivos da ecolinguística dessa região e nos fornecerá fundamentos para interpretar dados da contemporaneidade.

A faixa de fronteira brasileira compreende 16.886 quilômetros de comprimento e 150 quilômetros de largura, estendendo-se do Oiapoque ao Chuí, atravessando a floresta Amazônica ao longo da América do Sul. Ao longo dessa extensão, encontram-se 10 países, 11 Estados brasileiros, 588 municípios, 33 cidades gêmeas, 9 tríplices fronteiras, e, aproximadamente, 10 milhóes de habitantes (BRASIL, 2009).

Nesta faixa que corresponde a, aproximadamente, $27 \%$ do território nacional, o Amapá é uma "ilha”. Uma ilha no conjunto das zonas fronteiriças e das políticas públicas orientadas para as fronteiras brasileiras. 
Dividindo 730 quilômetros de fronteira com um enclave europeu na América do sul - a Guiana Francesa ${ }^{2}$-, o Amapá parece ser um território desconhecido e quase despercebido no âmbito das políticas de integração regional nas quais o Brasil se insere ${ }^{3}$. Em qualquer busca mais acurada no site do Itamaraty (Ministério das Relações Exteriores - MRE), é facilmente observável que a fronteira franco-brasileira parece ser um campo "desterritorializado", porquanto não se inclui, claramente, em nenhum dos departamentos $\left(\mathrm{DEU}^{4}, \mathrm{DAS}-\mathrm{I}^{5}, \mathrm{DAS}-\mathrm{II}^{6}, \mathrm{DACC}^{7}, \mathrm{DMAC}^{8}\right)$ que se ocupam das relaçôes político-econômicas entre o Brasil e os demais países da América do Sul e Caribe.

Isso se deve, obviamente, ao fato de a Guiana Francesa estar, geograficamente, localizada na América do Sul, mas ser, politicamente, um território pertencente à Europa e, por isso mesmo, estar fora dos projetos de integraçáo regional em curso nas Américas, fato que, logicamente, não anula a existência concreta dessa fronteira.

A faixa de fronteira se configura, historicamente, como uma região abandonada pelo Estado brasileiro, economicamente pouco desenvolvida, marcada pelas dificuldades de acesso a bens e serviços públicos, pela falta de coesão social e outros problemas peculiares às regióes fronteiriças (BRASIL, 2011).

2 Como Departamento Ultramarino Francês, a Guiana Francesa conserva a língua oficial da França, os padrões socioeconômicos, e administrativos, alguns hábitos culturais da França metropolitana e a moeda do Mercado Comum Europeu.

3 De acordo com informaçôes presentes no site do Itamaraty, o Brasil faz parte de 5 movimentos de promoção da integração regional entre países da América do Sul e Latina - UNASUL (União das Naçóes Sul-americanas), CALC (Cúpula da América Latina e do Caribe), CELAC (Comunidade dos Estados Latino-americanos e Caribenhos), MERCOSUL (Mercado Comum do Sul) e ALADI (Associação Latino-americana de Integração), porém, em nenhum deles aparecem acordos firmados entre o Brasil e a Guiana Francesa.

4 Departamento da Europa.

5 Departamento da América do Sul - I (Argentina, Bolívia, Paraguai e Uruguai).

6 Departamento da América do Sul - II (Chile, Equador, Peru, Colômbia, Venezuela, Guiana e Suriname).

7 Departamento da América Central e Caribe.

8 Departamento do México e América Central. 
De acordo com Porto e Silva (2009) e Porto (2010), a retomada do planejamento estratégico pelo governo federal brasileiro, por meio do Programa de Desenvolvimento da Faixa de Fronteira (PDFF), que propóe uma agenda concreta de intervençóes nas áreas limítrofes, permite uma superação da visão de fronteira como "espaço problema" e privilegia a região como um espaço pleno de oportunidades de desenvolvimento, de união com os países vizinhos e de valorização da cidadania.

Nesse sentido, é válido reafirmar que:

A fronteira deixa de ser elemento de separaçáo e transforma-se em faixa de contato. Ali, não apenas começam e terminam as soberanias formais, mas, sobretudo, é o lócus da cooperação e integraçáo cultural e comercial, do livre trânsito de pessoas, do compartilhamento de trabalho e de serviços e, em especial, da construção de um mercado comum (...) que permitirá à região sobreviver e ganhar escala para competir economicamente em um mundo tornado mais competitivo pela globalização (BRASIL, 2011, p. 18).

Todavia, em que pesem as múltiplas realidades existentes ao longo do espaço territorial brasileiro e a consciência delas, pelo poder público central, conforme registrado nos seminários de fronteira, há uma tendência tradicional no direito brasileiro de privilegiar regras e leis uniformes para todo o território nacional (BRASIL, 2011). Fatos dessa natureza implicam que as regras aplicadas à fronteira com o Uruguai ou a Argentina também se aplicam à fronteira com a Guiana Francesa e o Suriname. Essa tendência reveste a faixa de fronteira de contradiçóes e ambiguidades e revela, desta forma, que a extensão do território brasileiro e sua diversidade demandam, em alguns casos, a construção de políticas públicas diferenciadas para cada zona territorial. Esse deveria ser o caso do ensino de línguas. 


\section{1 - Fronteira franco-brasileira}

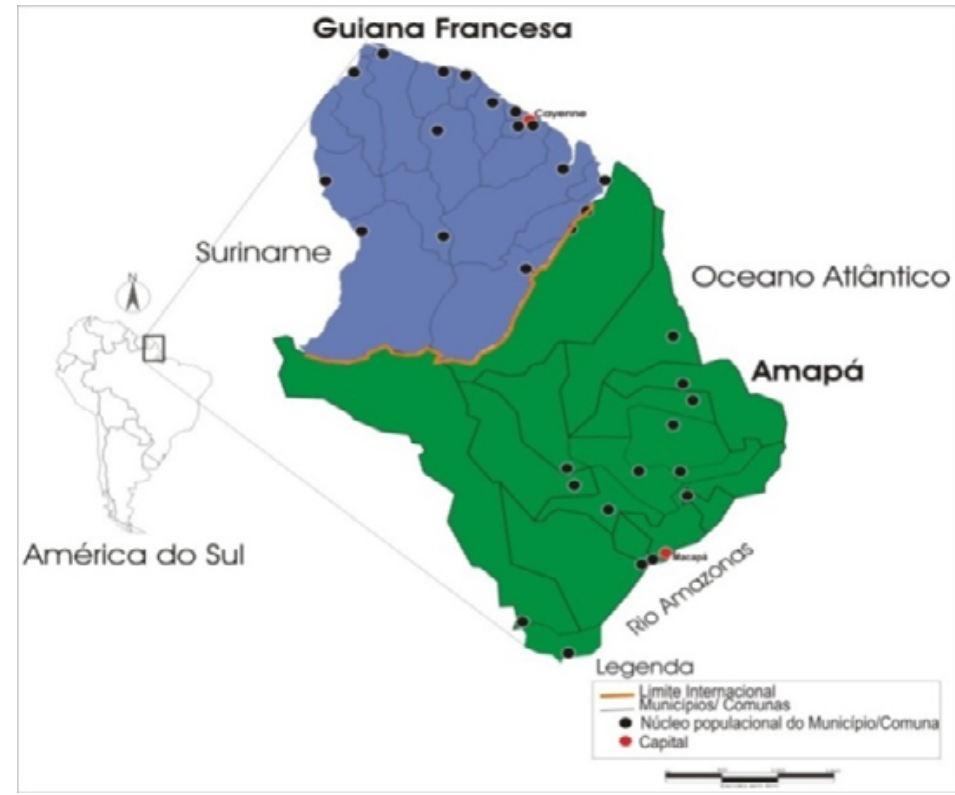

Fonte: MRE

Sendo a única fronteira brasileira com um território pertencente à União Europeia, a fronteira franco-brasileira não raro se vê excluída das negociações bilaterais entre países do cone sul e dos acordos nelas estabelecidos, uma vez que suas relaçóes intergovernamentais passam primeira e, inevitavelmente, entre Brasil e França, e não entre Amapá e Guiana Francesa. Não surpreende, portanto, que nos últimos seminários da faixa de fronteira, promovidos pelo Ministério das Relaçoóes Exteriores, raramente haja menção ou relato de ações desenvolvidas nessa fronteira.

Vale ressaltar que, no âmbito das relaçóes bilaterais sul-americanas, desenvolveram-se programas como Escolas Bilíngues de Fronteira, cidades-gêmeas e de ensino de português e espanhol nas áreas fronteiriças, projetos esses já em adiantada fase de desenvolvimento na maioria das áreas fronteiriças, mas apenas embrionários no Amapá, dadas, entre outras razóes, as especificidades da fronteira franco-brasileira e o fato de serem projetos diretamente vinculados à promoção do Mercosul e de suas línguas oficiais. 
No limite entre mercados (Mercosul e União Europeia), a zona de fronteira franco-brasileira busca afirmar e reforçar sua identidade sociocultural e linguística diferenciada das demais fronteiras brasileiras e construir mecanismos próprios de integração regional.

\section{Do lado de cá: o amapá}

O Amapá é uma das 27 unidades federadas do Brasil. Situado no extremo norte, o Estado faz fronteira ao norte com a Guiana Francesa, a noroeste com o Suriname, ao sul e a oeste com o Estado do Pará e a leste com o oceano Atlântico.

Localizado, estrategicamente, na foz do Amazonas, o território que hoje corresponde ao Estado do Amapá tem sua história marcada por eventos de exploração e tentativas de dominação estrangeiras. Por volta do final do século XVI, de acordo com Sarney \& Costa (1999), já se tinham registrado visitas de ingleses, irlandeses e holandeses à foz do Amazonas, na região então denominada de Cabo do Norte.

Segundo Porto (2010), a margem esquerda da foz do rio Amazonas tem historicamente atraído interesses externos, seja pelo domínio territorial, seja pelo uso de seus produtos ou seja pela fluidez ao interior do continente sul-americano. A história da colonização desse espaço territorial se mescla com a história de sua definitiva anexação ao território brasileiro. Constantemente invadido e anexado a diferentes reinos, o Amapá só se torna definitivamente brasileiro com o Laudo Suíço, em $1900^{9}$.

Com 142.827,897 km² de área e 16 municípios, o Amapá tem uma das menores densidades demográficas do país $\left(4,69\right.$ habitantes por $\left.\mathrm{km}^{2}\right)$, ainda que apresente uma das maiores taxas de crescimento demográfico (cerca de $3,4 \%$ ao ano), em razão, sobretudo, do intenso fluxo migratório das últimas décadas. De acordo com o censo 2010, o Amapá é o segundo Estado brasileiro que mais cresceu em termos proporcionais. Tendo menos de $30 \%$ de sua população como nativos, o Amapá se caracteriza por ser um Estado adotado por imigrantes de todas as partes do país.

$\overline{9}$ Na Suíça, em 1900, a questão do Contestado Franco-Brasileiro dá ganho de causa ao Brasil. 
Os 16 municípios amapaenses estão interligados por duas rodovias federais, a BR 156 e a BR 210, e quatro estaduais: a AP-010, AP-020, AP-030 e a AP-070. A BR-156 possui 822,9 km de extensão e atravessa diversos municípios, conectando a capital à cidade fronteiriça de Oiapoque. Ela faz parte do projeto de criação da Transguianense, isto é, uma rodovia de $2.346 \mathrm{~km}$ que deverá interligar as capitais dos Estados do Amapá e de Roraima, passando pela Guiana Francesa, pelo Suriname e pela Guiana. A Transguianense faz parte de um projeto maior denominado Arco Norte. Sua inauguração está condicionada à pavimentação total da BR-156 e à construção da ponte binacional, já concluída.

Figura 2 - Rodovia Transguianense

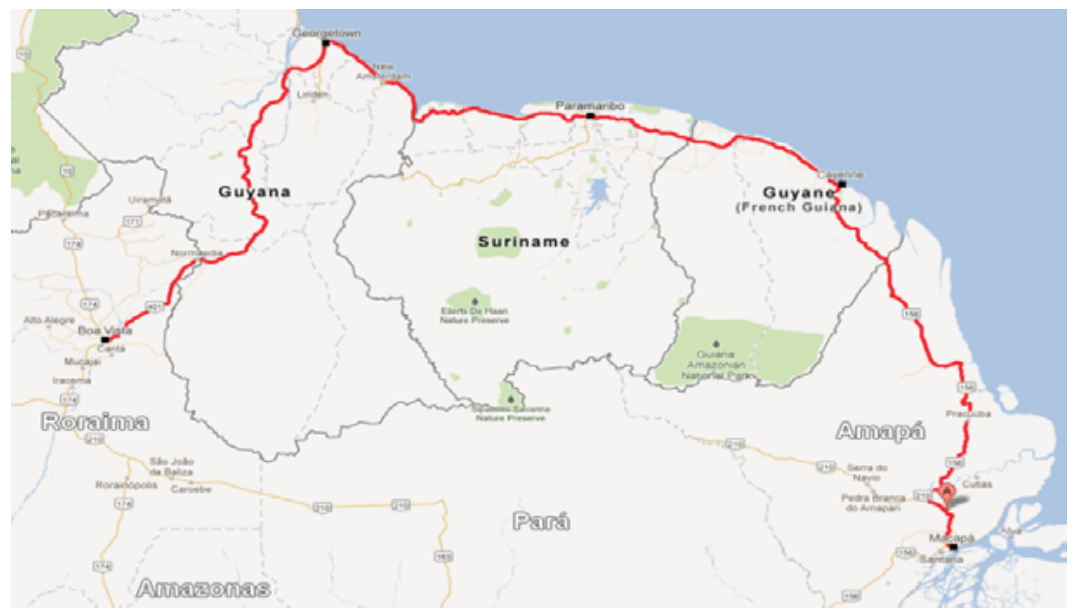

Fonte: realidadesurbanas.blogspot.com.br

Entre o Amapá e qualquer outra unidade federada brasileira só há transporte fluvial ou aéreo. A primeira conexáo terrestre do Amapá com um território contíguo é exatamente a Ponte Binacional que o interliga à Guiana Francesa. Em consequência, mesmo que seja muito comum, nos dias atuais, perceber o alto índice de migração para o Estado, pela identificação das placas dos veículos que circulam nas cidades, aqueles que mais chamam atenção são os automóveis provenientes da Guiana Francesa, com suas identificaçóes em azul e branco. 
Em contrapartida, os rios constituem as verdadeiras "estradas vicinais" da Amazônia. Em barcos pequenos ou grandes, em canoas, cascos, catraias ou batelóes, com eles pode-se ir a qualquer localidade do Estado e transportar qualquer tipo de mercadoria ou passageiro. É através deles que entram carros e saem minérios, entram móveis e saem polpas de frutas; neles se instalam escolas, bibliotecas, hospitais, e mesmo os tribunais itinerantes. Fontes de riqueza, de alimento e mesmo de contato, são os rios que ligam o Amapá ao Brasil.

A economia amapaense está ancorada, principalmente, no setor terciário (comércio, educação, saúde, telecomunicações, serviços de informática, seguros, transporte, limpeza, alimentação, turismo etc.). A área de serviços representa $85,8 \%$ do PIB do Amapá. O comércio varejista é uma das principais fontes de renda do Estado, representando quase 50\% deste setor.

Quanto aos aspectos educativos, dados preliminares do Censo 2010 apontam que $92 \%$ da população amapaense, acima de 15 anos, é alfabetizada. O tempo médio de escolaridade do amapaense é de oito anos de estudos, acima da taxa média da regiáo Norte $(6,7)$ e mesmo do Brasil, que é de 7,2 anos. Porém, se, por um lado, no Amapá registra-se um dos maiores índices de investimentos por aluno do País (cerca de $\mathrm{R} \$ 3.752,39$ ), segundo dados do MEC/INEP, por outro, é onde há uma das menores taxas de professores com formação superior nos primeiros anos de ensino (da creche à quinta série).

Estes índices estão diretamente relacionados ao pouco investimento feito no ensino superior durante os 45 anos em que o Amapá esteve sob a administração direta do Governo Federal. Nenhuma universidade foi criada nesse período (a primeira universidade do Estado - UNIFAP - só abriu seus primeiros cursos na década de 1990), e todos os amapaenses que frequentaram um curso superior, até o final da década de 1980, tiveram que se deslocar para outras unidades da federação, principalmente para o vizinho Estado do Pará.

Etnicamente, o Amapá possui uma população bastante miscigenada, razão pela qual é constituído por 74,4\% de pardos, $20 \%$ de brancos, 4,5\% de negros e $0,8 \%$ de indígenas, números que revelam, por um lado, uma completa inversão numérica dos grupos étnicos que deram início à colonização, uma vez que os indígenas e negros estão reduzidos a um contingente minoritário, e, por outro, indicam uma forte mesclagem entre negros, índios e brancos.

Quanto à população ameríndia, atualmente habitam o Amapá cinco grupos descendentes das naçóes Tucujus, Maraon e Aroaqui: Os Palikur, os 
Galibis Kaliña, os Galibis Marworno, os Karipunas e os Waiäpis. A circulação desses grupos na regiáo fronteiriça, historicamente, é elemento decisivo tanto do contato que deu origem aos crioulos da regiáo quanto da perda linguística registrada em alguns grupos indígenas na região.

Atualmente seis línguas estão em uso, com diferentes graus de domínio, entre comunidades linguísticas distintas no Estado do Amapá: o português brasileiro, o francês, o paikwaki, o kheuol, o créole guianense e a língua indígena waiäpi.

\section{Do outro lado do rio: la guyane française}

Considerada uma das sete regiōes ultra periféricas ${ }^{10} \mathrm{da}$ Uniāo Europeia, a Guiana Francesa é oficialmente um território francês na América do Sul. Situado entre o Brasil e o Suriname, ela divide $520 \mathrm{~km}$ de fronteira com o Suriname e cerca de $700 \mathrm{~km}$ com o Brasil, constituindo esta última a maior fronteira de um departamento francês.

Tendo pouco menos de $90.000 \mathrm{~km}^{2}$, divididos em 22 municípios, a Guiana Francesa é o maior departamento francês em superfície (equivalente a $16 \%$ do território metropolitano) e, proporcionalmente, o menos povoado. Com uma população estimada em 232.223 habitantes ${ }^{11}$, a Guiana Francesa tem uma baixíssima densidade demográfica (menos de 3 hab. $/ \mathrm{km}^{2}$ ), e a maioria da população está concentrada na capital, Caiena.

A progressão demográfica guianense, no entanto, é acentuada, cerca de $3,6 \%$ ao ano, a maior dentre todos os departamentos franceses e as regióes ultra periféricas. Para Mureau (2011), este crescimento está relacionado, principalmente, a uma alta taxa de natalidade e não exatamente à migraçáo, ainda que esta seja altamente relevante.

A Guiana tem uma longa tradição de imigração; sua população, segundo estimativas do INSEE ${ }^{12}$, é composta por $38 \%$ de créoles $^{13}, 6 \%$ de

$10 \mathrm{O}$ conceito de regiấo ultra periférica nasceu do reconhecimento de dificuldades permanentes que atingem algumas regiōes europeias e que dificultam o desenvolvimento econômico: distanciamento, insularidade, superfície, relevo, clima difícil e dependência econômica. Étude du besoin guyanais: "Égalités des chances sur le territoire européen: le besoin guianais”, 2004.

11 Dados da Câmara de Comércio e da Indústria da Guiana -CCIG- de 2010.

12 Institut Nacional de la Statistique et des Études Économiques.

13 Créoles são todos os descendentes de escravos africanos, mestiços ou não. Porém, eles mes- 
Bushinengue ${ }^{14}, 5 \%$ de indígenas, $10 \%$ de franceses metropolitanos, $4 \%$ de antilhanos, $4 \%$ de chineses, $1 \%$ de Hmongs $^{15}$ e outros $32 \%$ de diferentes outros grupos, entre os quais, os brasileiros. Do total da população da Guiana Francesa, cerca de $30 \%$ é composta de estrangeiros.

Quanto ao cenário linguístico, de acordo com Alby e Léglise (2007), há cerca de 30 línguas sendo utilizadas na Guiana Francesa, independentemente de sua classificação como primeira ou segunda língua, conforme tabela seguinte:

Quadro 1 - Línguas faladas na Guiana Francesa

\begin{tabular}{|c|c|}
\hline 6 Línguas indígenas & $\begin{array}{l}\text { kalina, wayana, wayampi, palhikwaki } \\
\text { ou palikur, lokonoou arawak, teko ou } \\
\text { émerillon }\end{array}$ \\
\hline 5 Crioulos de base francesa & $\begin{array}{l}\text { Crioulo guianense, crioulo haitiano, } \\
\text { crioulo martiniquense, crioulo } \\
\text { guadalupeano, crioulo de Saint-Lucie }\end{array}$ \\
\hline 4 Crioulos de base inglesa & $\begin{array}{l}\text { Nenge(e) e suas variaçóes (aluku, ndyuka, } \\
\text { pamaka e sranan tongo }\end{array}$ \\
\hline $\begin{array}{l}1 \text { Crioulo de base inglesa relexificado } \\
\text { pelo português }\end{array}$ & Saamaka \\
\hline 5 Línguas europeias & $\begin{array}{l}\text { Francês, português, inglês da Guiana, } \\
\text { holandês do Suriname e espanhol de } \\
\text { Santo Domingo e países sul-americanos. }\end{array}$ \\
\hline 3 Línguas asiáticas & Hmong, hakka e cantonais \\
\hline
\end{tabular}

Fonte: Quadro elaborado pela autora a partir de Alby e Léglise (2007)

Considerada como "verdadeira e única" porta de entrada potencial da Europa na América do Sul, a Guiana sofre de um "enclavamento" que

mos distinguem os créoles guianenses dos não guianenses (guadalupenses, martiniquenses, haitianos).

14 Negros descendentes de antigos escravos surinamenses que teriam se rebelado e ido morar, como seus ancestrais, na floresta. É em razão de seu modo de vida que eles ficaram conhecidos como bush negroes ou nègres des bois - negros das matas.

15 Comunidade de descendentes asiáticos provenientes do sul da China, do norte do Vietnã ou do Laos. Na Guiana, eles chegaram como refugiados em 1977, com o propósito de povoar a Guiana e fortalecer a agricultura, principalmente a plantação de arroz. 
diminui consideravelmente as vantagens de sua posição geoestratégica. $\mathrm{O}$ isolamento relativo ao continente europeu e à França hexagonal é agravado pela situação de quase monopólio das companhias de transporte aéreo e marítimo; por outro lado, a comunicação com o restante da América Latina é dificultada pelo baixo número de bases estruturais portuárias e aeroportuárias. Uma grande expectativa se concentra no eixo transamazônico, uma vez que a ligação da Guiana com o Brasil através da ponte construída sobre o rio Oiapoque abre espaço para novas perspectivas nas relaçóes econômicas na região.

Para o governo francês, de acordo com Mureau (2011), a posição geoestratégica da Guiana Francesa na América do Sul permanece largamente subexplorada não apenas em termos de intercâmbios comerciais, mas também culturais, técnicos ou universitários.

A exemplo do Amapá no lado brasileiro, a economia guianense está baseada no setor terciário, no funcionalismo público ${ }^{16}$ e, principalmente, na atividade espacial desenvolvida na Base Espacial de Kourou. O desenvolvimento dos setores primários e industriais se vê limitado pelo distanciamento da metrópole e pelo isolamento regional. Em contrapartida, a Guiana tem vivenciado, na última década, uma fase de crescimento econômico que contrasta com o contexto internacional, sobretudo com o europeu.

Vale salientar ainda que, na Guiana Francesa, a maioria da população (créole, sobretudo, e indígena) é bilíngue, falante do crioulo guianense e do francês, com diferentes graus de domínio dessas línguas; porém, de acordo com Rattier \& Robinson (2010, p. 5), já é possível encontrar jovens guianenses francófonos monolíngues, devido ao aumento e à obrigatoriedade do período de escolaridade e ao papel importante que ocupa a televisão como fonte de lazer para os jovens.

\section{Panorama ecolinguístico da fronteira franco-brasileira}

O quadro fronteiriço esboçado neste trabalho nos permite compreender, em linhas gerais, as imbricadas relaçóes sociais, históricas e interpessoais estabelecidas no contexto da fronteira e esboçadas pelo viés das línguas em

16 Dados do INSEE indicam que 30\% dos trabalhadores da Guiana ocupam um cargo público. 
presença. $\mathrm{O}$ delineamento da ecologia da fronteira, que propomos a partir de então, engloba a situação das línguas, considera os discursos, os modos de dizer e de nomear, a circulação, entre outros.

Tomando como referência o modelo gravitacional de Calvet (1999), identificamos na ecologia das línguas da fronteira duas línguas supercentrais, tanto do ponto de vista global quanto do local: o português e o francês. Elas ocupam as funções e características de línguas supercentrais (LSC): são as línguas dominadas pela maioria, possuem status de oficialidade, são usadas nas relaçôes oficiais (instituicões, escolas, comércio) e entre os grupos linguísticos majoritários bilíngues ou monolíngues.

Em termos demográficos, o português é a principal língua da fronteira: a população falante do português no Amapá é duas vezes a população da Guiana. Em termos de valor econômico, o francês ocupa essa mesma posição. $\mathrm{O}$ valor do euro redimensiona a importância da língua na regiáo e repercute na aprendizagem da mesma.

Em torno delas, circulando pelo espaço fronteiriço que delimitamos em linha vertical de uma capital a outra, passando pelo núcleo da zona fronteiriça que concentram as relaçóes de encontro, gravitam: uma língua central (LC), que é o crioulo guianense falado pela maioria da população indígena e não indígena como língua veicular, ou seja, uma espécie de passe par tout nas relaçóes informais entre grupos etnolinguísticos minoritários diferentes, e diversas línguas periféricas (LPF) que circulam em ambos os lados da fronteira e com as quais os brasileiros também entram em contato por causa do movimento de ir e vir fronteiriço. Nesse âmbito, estão os diferentes crioulos de base francesa e portuguesa, as línguas indígenas, as línguas asiáticas, e mesmo as línguas europeias de baixo impacto nas relações entre falantes fronteiriços.

A figura a seguir apresenta uma proposta de leitura da relação gravitacional das línguas na fronteira franco-brasileira. Sem a pretensão de estabelecer uma análise exaustiva das línguas que estão mais frequentemente em contato, identificamos no meio ambiente fronteiriço pelo menos 30 línguas em presença (cf. ALBY \& LÉGLISE, 2007), nem todas simultaneamente em contato, tampouco demonstradas, na totalidade, no quadro. 
Figura 3 - Relação gravitacional das línguas na fronteira franco-brasileira

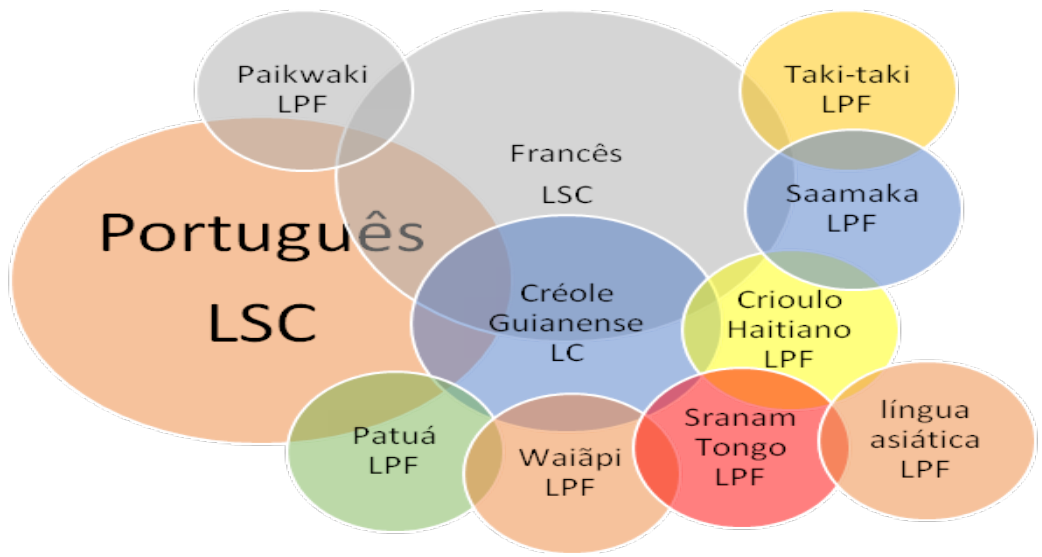

Fonte: Elaborada pela autora

As duas línguas consideradas supercentrais pelo modelo gravitacional de Calvet (1999) se estendem em um contínuo que as situam de um ponto a outro como língua materna, língua segunda e língua estrangeira, ambas em sentido diametralmente inverso: o português em direção à Guiana Francesa e o francês em direção ao Estado do Amapá. Na interseção dos territórios, estão as cidades gêmeas, Oiapoque e Saint-Georges, local onde o status das línguas (supercentrais e periféricas) é muito mais fluido e menos delimitado.

Figura 4 - Contínuo das línguas na zona fronteiriça

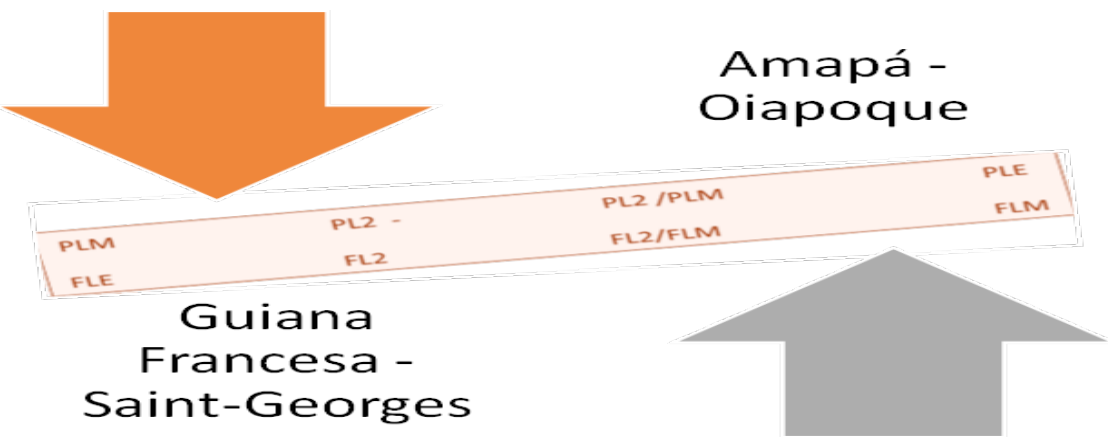

Fonte: Elaborada pela autora 
A fronteira franco-brasileira está claramente delimitada por uma barreira física, o rio Oiapoque. Essa linha demarcatória é, também, uma das razóes pelas quais se configuraram dois ecossistemas linguísticos centrais (o da língua portuguesa e o da língua francesa) que não produziram entre si uma terceira língua. Processo Diferente daquele ocorrido quando essa delimitação não estava definida, cuja mobilidade das populaçóes indígenas e não indígenas deu origem aos crioulos de base francesa e portuguesa na região, como é o caso do Kuéhol e do créole guianense, falado atualmente pelas populaçôes indígenas de ambos os lados da fronteira.

Se, por um lado, a proximidade não deu origem a uma língua mista de fronteira, como tem ocorrido em outras fronteiras do país, por outro, desenvolveu grupos sociais bilíngues e multilíngues. É o caso das tribos indígenas que, em geral, usam duas ou três línguas da região, das famílias mistas que se formaram entre brasileiros e franceses ao longo da fronteira, além do bilinguismo português-francês decorrente da migração, do estímulo produzido pelo mercado de trabalho e das relaçóes socioculturais já consolidadas.

A porosidade da zona fronteiriça que facilita a circulação espacial faz com que, no movimento de famílias inteiras, nos dois sentidos da BR-156, muito mais no sentido da Guiana, mas não exclusivamente, originem-se crianças que têm o francês como segunda língua em território brasileiro ou em território francês, ou ainda que, em território francês, tenham o português como língua materna, o créole como segunda língua e o francês como língua de escolarização.

Por outro lado, as relaçóes estabelecidas nos ecossistemas linguísticos da fronteira, marcadas na economia, na educação e nas relaçôes interpessoais, decorrem tanto do processo de colonização da região (aspectos históricos) quanto da busca pela integração da fronteira (cooperação). Tal qual a influência econômica e cultural norte-americana no mundo, no Amapá, a língua francesa se faz cada vez mais presente no dia a dia da comunidade. Ela se revela nos nomes das crianças (Steffani, Elodie, Loran, Caroline, Nadine, Katrine, entre outros) e dos estabelecimentos comerciais (Palmiste, Quiosque, La Roche, Femme Fatale, Paris, etc.), nos cardápios de alguns restaurantes traduzidos para o francês, e até nos discursos e nas representaçôes sobre a língua que circulam nos diferentes círculos sociais.

Em função do contexto fronteiriço, não é raro ouvir assertivas do tipo: “o 
francês deveria ser obrigatório no Amapá!", "o francês é difícil, mas tem que aprender!", "eu preciso aprender francês", "o francês deveria estar em todas as escolas do Estado", etc., ou seja, falar francês no Amapá é, frequentemente, percebido como uma obrigação/necessidade inerente ao contexto geopolítico. É igualmente comum perceber, nos discursos, que as pessoas se ressentem ou se envergonham de "ainda não falar", ou por "ainda não ter procurado um curso". Tal fato deixa entrever a importância da língua do país vizinho para a população brasileira no Amapá.

No contexto econômico, sendo o euro uma moeda mais forte que o real, esse valor repercute nas relaçóes socioeconômicas e, consequentemente, linguísticas. Se a relaçáo da moeda é de aproximadamente quatro reais para um euro, as consequências são de diferentes ordens. Por um lado, o poder econômico dos guianenses faz deles clientes preferenciais no Amapá, e a recíproca é verdadeira no sentido de que no Amapá o poder de compra do guianense se multiplica por quatro. Assim, vir ao Brasil (e, nesse caso, Oiapoque já é Brasil) é, proporcionalmente, mais econômico do que se deslocar até a Europa, ou mesmo para outros estados brasileiros.

Esse poder econômico se reflete na questão linguística. Falar a língua do "cliente", do "vizinho", do "turista" ou do "cidadão" é percebido como fundamental, fazendo com que proprietários e funcionários de hotéis, bares, restaurantes, agências de câmbio, agências de viagens, supermercados, lojistas em geral, taxistas, agentes públicos (policiais militares, civis, rodoviários, bombeiros, agentes de saúde, juízes, advogados, etc.) busquem aprender a língua supercentral do país vizinho, e, por conseguinte, tornem-se bilíngues por meio do ensino. Como observa Couto $(2011$, p.390) "quer queiramos, quer não, em geral, [o indivíduo] adapta-se ao que é mais conveniente, econômico ou ao mais forte". Neste caso, tornar-se bilíngue é um ato de adaptação.

Esse processo de adaptaçáo fica claramente demonstrado nos índices de inscrição para o processo seletivo do Centro Estadual de Língua e Cultura Francesa Danielle Mitterrand, onde cerca de 7000 (sete mil) pessoas, por ano, concorrem a 450 vagas, no quantitativo de instituiçóes públicas e privadas que solicitam vagas ou abertura de turmas para seus funcionários (em 2012, foram 102 ofícios) e na diversidade de áreas profissionais daqueles que frequentam o curso.

A figura a seguir é representativa da demanda de vagas no CELCFDM, por área, em 2012. 
Figura 5 - Demanda de ensino de francês por área

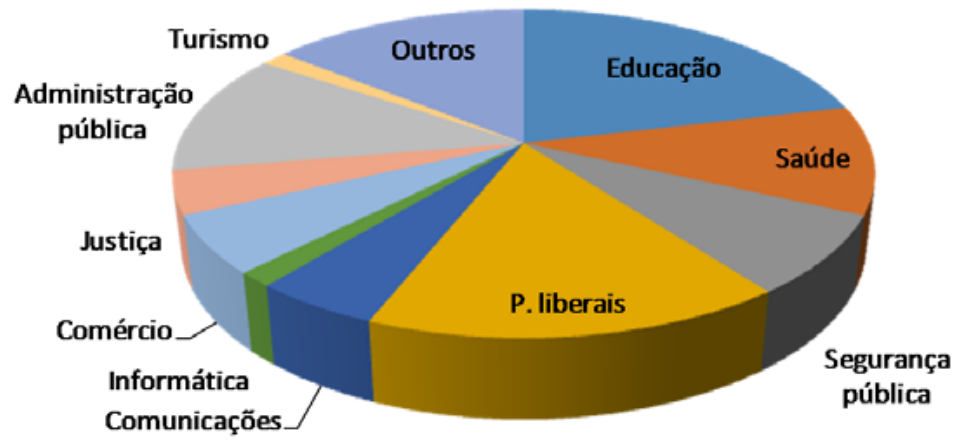

Fonte: Elaborada por Day (2012)

Por outro lado, o valor do euro também faz da Guiana um eldorado, principalmente para a camada mais baixa e menos escolarizada da população, que vê no trabalho na Guiana (clandestino na maioria das vezes) uma forma de aumentar seu poder aquisitivo no Brasil. Ou seja, ganhar em euro e gastar em real é a situação ideal para muitas famílias. Essa situação também tem repercussóes linguísticas, e a mais clara delas é a aprendizagem do francês e do créole, que ocorre em situação de imersão para essas famílias. Falar francês, nesses casos, não denota status social ou luxo intelectual. Em terras amapaenses, é mais comum encontrar falantes fluentes de francês e crioulo guianense nas áreas periféricas do que nos círculos mais abastados da sociedade.

$\mathrm{Na}$ ecologia fundamental das línguas da fronteira, português e francês têm papel central, seja como línguas oficiais e maternas, seja como segundas línguas ou línguas estrangeiras. Elas entremeiam tanto as relaçóes sociais quanto as econômicas e políticas, dados estes corroborados por elementos sócio-históricos e geofísicos da região.

\section{Considerações finais}

A principal contribuição da ecolinguística no âmbito da política linguística educativa brasileira está em delinear mais claramente os contornos da relação língua, povo e território. Recorrer aos vínculos sócio-históricos e espaço-tem- 
porais constitutivos de uma relação interlinguística entre comunidades de línguas distintas, como observamos entre Amapá e Guiana Francesa, é, sobretudo, não obliterar a essência identitária local em prol de um mundo globalizado.

Não se pode escolher uma língua (qualquer que seja seu status) e determinar sua função em uma sociedade sem considerar os usos sociais que se faz dela. É necessário ater-se às demandas originadas no bojo de questôes políticas, econômicas, culturais e interpessoais.

Diante das dimensóes espaço-culturais brasileiras, uma política linguística educativa não pode ser, senão, para usar os termos de Grin (2005), uma política de gestão da diversidade. Tomar a diversidade como fundamento da política linguística implica considerá-la em todos os seus aspectos e observá-la em todos os seus cenários.

Por maior que seja a unidade em um estado-nação, toda população será, em alguma medida, heterogênea. A diferença também constitui a unidade. Ser a única fronteira com um território não hispânico, antes, deveria ser motivo de valorização da diferença, e não de tentativa de homogeneização.

A presença histórica da língua francesa na fronteira franco-brasileira situa essa língua num contínuo que a coloca em um extremo como língua oficial e materna, e, em outro, como língua segunda e estrangeira. Essa configuração não apenas a identifica como língua de presença efetiva nas inter-relaçóes entre os povos da fronteira, mas a coloca em lugar de destaque no âmbito da política linguística de ensino de língua estrangeira na regiâo, fato que contrasta com a atual política linguística nacional para esse ensino, que privilegia o ensino do inglês e do espanhol e desconsidera as diferenças regionais.

\section{Referências}

ALBY, S. et LEGLISE, I. Le paysage sociolinguistique de la Guyane. Un état desieux des recherches. In : MAM-LAM-FOUCK, S. (ed). Comprendre la Guyane d'aujourd'hui. Cayenne: Ibis Rouge Editions, 2007. p. 469-479.

BRASIL. Faixa de fronteira. Programa de promoção do desenvolvimento da faixa de fronteira. Ministério da Integração Nacional. Secretaria de programas regionais, Brasilia, 2009.

BRASIL. Seminário Perspectivas para áreas de fronteira. Presidência da República. Gabinete de Segurança Institucional. Secretaria de Acompanhamento e Estudos Institucionais. Brasília, 2011. 
CALVET, Louis-Jean. Pour une écologie des langues du monde. Paris : Plon, 1999. 304p.

CAPIBERIBE, Artionka. Iyuwti kavanyahaki, le chapeau cérémoniel Palikur. Catálogo da Exposição "Índios no Brasil". International Arts Festival Europália, Bruxelas, 2011.

COUTO, Hildo H. Ecolinguistica. Estudo das relaçóes entre língua e meio ambiente. Brasília: Thesaurus Editora, 2007. 462p.

. Linguistica, Ecologia e Ecolinguística: contato de línguas. Sáo Paulo: Contexto, 2009. 192p.

. Contato entre português e espanhol na fronteira Brasil-Uruguai. In: MELLO, H.; ALTENHOFEN, C.; RASO, T.; (Orgs). Os contatos linguísticos no Brasil. Belo Horizonte: Editora UFMG, 2011. p.369-395.

DUTRA, Denise P. O Ensino de L2 no Brasil. In: MELLO, H.; ALTENHOFEN, C.; RASO, T.; (Org.). Os contatos linguísticos no Brasil. Belo Horizonte: Editora UFMG, 2011. p.445-460.

GRIN, François. L'enseignement des langues étrangères comme politique publique. Genève: SRED, 2005. 49p.

HAUGEN, E. The Ecology of language. Standford, Standford University Press, 1972.

MACKEY, Wiliam F. Bilinguisme et Contact des langues. Editions Klincksieck, Paris, 1976. 540p.

MUFWENE, S.S. The ecology of language evolution. Cambridge University Press, Cambridge, 2001. 276p.

MUREAU, Cedric. L'investissement stimule la croissance guyanaise. 2011. Disponível em: < www.iedon.fr>. Acesso em 17 de novembro de 2012.

PORTO, J. NASCIMENTO, D. (org.) Interaçôes fronteiriças no platô das Guianas: Novas construções, novas territorialidades. Macapá, Editora, 2010. $214 \mathrm{p}$.

PORTO, J. L. R.; SILVA, G. V. Novos usos e (re)construções da condição fronteiriça amapaense. In: Novos Cadernos, 12 (2), p. 253-297, Belém, 2009. 


\title{
THE ISLAND AMAPA - ECOLINGUISTICS PANORAMA OF THE FRANCO-BRAZILIAN BORDER
}

\begin{abstract}
This article presents an overview of the Franco- Brazilian border from the epistemological foundations of Ecolinguistics. The theoretical-methodological apparatus used in the format of this table is based on the prospect of Ecolinguistics Calvet (1996), the ecosystem approach proposed by Couto (2007), besides the methodological foundations of descriptive study of ethnographic nature.
\end{abstract}

KEYWORDS: Linguistic Policy; Ecolinguistics; Franco-Brazilian border

Recebido em: 31/05/2016

Aprovado em: 18/10/2016 